\title{
Evaluation of the Preventive Effect of Selenium on Acute Kidney Injury following On-pump Cardiac Surgery
}

\author{
Abbas Ali Zeraati ${ }^{1}$, Shahram Amini ${ }^{2}$, Mohammad Samadi ${ }^{3}$, Hasan Mortazi ${ }^{4}$, Tina Zeraati ${ }^{5}$ and Katayoon Samadi ${ }^{1, *}$ \\ ${ }^{1}$ Kidney Transplantation Complications Research Center, Department of Internal Medicine, Imam Reza Hospital, Mashhad University of Medical Sciences, \\ Mashhad, Iran \\ ${ }^{2}$ Lung Research Center, Imam Reza Hospital, School of Medicine, Mashhad University of Medical Sciences, Mashhad, Iran \\ ${ }^{3}$ General Practitioner, Mashhad, Iran \\ ${ }^{4}$ Internal Medicine Student, School of Medicine, Mashhad University of Medical Sciences, Mashhad, Iran \\ ${ }^{5}$ Medical Student, School of Medicine, Mashhad University of Medical Sciences, Mashhad, Iran
}

* Corresponding author: Katayoon Samadi, Kidney Transplantation Complications Research Center, Department of Internal Medicine, Imam Reza Hospital, Mashhad University of Medical Sciences, Mashhad, Iran. Tel: +989155139303; Email: kt_samadi@yahoo.com

Received 2020 November 26; Revised 2021 May 31; Accepted 2021 August 12.

\begin{abstract}
Background: Patients undergoing on-pump cardiac surgery are at risk of postoperative acute kidney injury (AKI). This is mainly due to some ischemic events and also pre-and postoperative stress responses which can result in postoperative organ dysfunction. Selenium (Se) as an antioxidant may help reduce inflammation and subsequent related complications.

Objectives: This study aimed to test if administration of oral Se complement before and after the on-pump cardiac surgery can reduce the incidence or severity of AKI following the operation.

Methods: In this randomized double-blind trial, the patients who were a candidate for on-pump cardiac surgery were randomly divided into two groups of intervention and control who received Se $(n=60)$ or nothing $(n=60)$, respectively. In the Se group, $500 \mu g$ of Se was administrated orally 14 and $2 \mathrm{~h}$ before surgery and every $12 \mathrm{~h}$ postoperatively for 2 days (overall $3000 \mu \mathrm{g}$ ), while the control group only received the routine and standard care. The patients were closely observed for the incidence and severity of postoperative AKI, using both Risk/Injury/Failure/Loss/End-stage (RIFLE) and the Acute Kidney Injury Network (AKIN) criteria.

Results: The study sample included $46(38.3 \%)$ males and $74(61.7 \%)$ females with a mean \pm SD age of $52.8 \pm 16.7$ years. Both groups were similar in terms of demographic characteristics, comorbidities, and Euro-SCORE. According to the RIFLE criteria, AKI occurred in 11 $(17.9 \%)$ and $13(21.4 \%)$ patients in the Se and control group, respectively. However, based on AKIN criteria, there were 17 (28.6\%) and $21(35.7 \%)$ cases of AKI in the Se and the control group, respectively ( $\mathrm{P}=0.73)$. The most frequent stage of AKI among patients was the first stage in both groups and the highest rate of AKI was observed within 3-4 days after the surgery in both groups.

Conclusion: The obtained results did not approve the effect of Se in AKI prevention in coronary artery bypass grafting patients.
\end{abstract}

Keywords: Acute kidney injury, Cardiac surgery, On-pump, Selenium

\section{Background}

Cardiac surgery-associated acute kidney injury (CSA-AKI) is a serious and frequent complication among patients who suffer from congenital or acquired heart diseases (1-3). The incidence of CSAAKI ranges from $5 \%$ to $45 \%(1,2,4,5)$ and increases the duration of hospitalization and healthcare costs as well as in-hospital and long-term morbidity and mortality (2, 4-7). Moreover, CSA-AKI results in the prolongation of mechanical ventilation and ICU stay renal replacement therapy requirement, and the development of chronic kidney disease with a high mortality rate $(1,2)$. Factors contributing to the development of CSA-AKI include exogenous and endogenous toxins, ischemia-reperfusion injury, metabolic abnormalities, microemboli, inflammation, neurohormonal activation, and oxidative stress $(6,7)$. A slight elevation in serum creatinine levels after cardiac surgery has been associated with poor outcomes and renal replacement therapy further increased the mortality rate $(2,7,8)$.

Many investigations have attempted to find a pharmacologic therapy for the prevention of postoperative AKI. Despite several efforts to find pharmaceutical prevention and treatment of postoperative AKI only a few measures can be recommended which include the preservation of hemodynamic stability by fluid management or vasopressor and inotrope, some renal vasodilators, and volume expansion (9). Furthermore, studies revealed that diuretic agents can improve urine output and facilitate hemodynamic management. Treatment with mannitol and osmotic diuretic leads to renal vasodilation and increases renal blood flow while it has no effect on filtration fraction and renal oxygenation $(7,10)$. It is worth mentioning that even the administration of atrial natriuretic peptide is not effective in CSA-AKI treatment (11).

Selenium (Se), an essential trace element, is an antioxidant that acts as a radical scavenger and is responsible for the normalization of all selenoenzymes (selenoproteins), such as thioredoxin reductase and intracellular glutathione peroxidase. It also seems that Se can decrease the need for renal replacement therapy $(7,12,13)$. Pretreatment with antioxidants, such as Se is

Copyright (c) 2021, Author(s). This is an open-access article distributed under the terms of the Creative Commons Attribution-NonCommercial 4.0 International License (http://creativecommons.org/licenses/by-nc/4.0/) which permits copy and redistribute the material just in noncommercial usages, provided the original work is properly cited 
suggested to attenuate the inflammation. Se plays an important role in the anti-inflammatory process and elevation of antioxidant capacities via at least 25 selenoproteins including the glutathione peroxidases, thioredoxin reductases, selenoprotein $P$, and iodothyronine deiodinases (9). There is increasing evidence suggesting that Se serum concentration declines the following surgery and remains low for a period of several days to weeks. This reduction is associated with the elevation of reactive oxygen species (ROS) and the severity of illness $(6,16,17)$. On the other hand, post-injury normalization of Se status does not reduce oxidative stress (17). Therefore, it is postulated that a preemptive approach is preferred.

\section{Objectives}

The present study aimed to investigate the effect of Se on the prevention of acute kidney injury after on-pump cardiac surgery.

\section{Methods}

This randomized double-blind clinical trial included 120 candidates for elective on-pump cardiac surgery. The written informed consent was obtained from the participants at the beginning of the study. Patients were excluded from the study if they had renal structural abnormalities, renal failure, single kidney, heart failure with an ejection fraction $(E F)<35 \%$, severe malnutrition, and those with a history of cardiac arrest with prolonged Creactive protein (CPR), dip vein thrombosis (DVT) in the last 6 months, allergy/hypersensitivity to Se, surgery duration more than $5 \mathrm{~h}$, reception of more than 2 IU packed red blood cell (RBC) during the surgery, intra or postoperative application of intraaortic balloon pump, or application of more than one vasopressor/inotrope agent.

Patients were randomly divided into two groups of Se $(n=60)$ and placebo or control $(n=60)$ using a random number table. The Se group received $500 \mu \mathrm{g}$ of Se orally 14 and $2 \mathrm{~h}$ before surgery and every $12 \mathrm{~h}$ postoperatively for 2 days (overall $3000 \mu \mathrm{g}$ ), while the control group only received the routine and standard care.

All patients received $1 \mathrm{mg}$ oral lorazepam the night before surgery, as well as intramuscular morphine $0.05 \mathrm{mg} / \mathrm{Kg}$ and promethazine $25 \mathrm{mg}$ one hour before surgery. Anesthesia was induced with $10-15 \mu \mathrm{g} / \mathrm{Kg}$ fentanyl and $0.1 \mathrm{mg} / \mathrm{Kg}$ midazolam followed by 0.15 $\mathrm{mg} / \mathrm{Kg}$ atracurium for endotracheal intubation. Propofol (50-100 $\mu \mathrm{g} / \mathrm{Kg} / \mathrm{min})$, fentanyl (2-3 $\mu \mathrm{g} / \mathrm{Kg} / \mathrm{min}$ ), and atracurium (3 $\mu \mathrm{g} / \mathrm{Kg} / \mathrm{min}$ ) was infused to maintain the anesthetic state. Mean arterial pressure (MAP) was maintained between 60 to 80 mmHg. Transfusion was conducted in case of hemoglobin less than $8 \mathrm{mg} / \mathrm{dL}$ or $8-10 \mathrm{mg} / \mathrm{dL}$ with ScV02 $<70 \%$, lactate more than $4 \mathrm{mmol} / \mathrm{L}$, or the need for two vasopressors to maintain MAP above $60 \mathrm{mmHg}$.

We explored the patients for the development of AKI until they were discharged from the hospital using the RIFLE and acute kidney injury network (AKIN) criteria. The glomerular filtration rate of the patients was calculated using the MDRD equation, assuming a steady-state renal function.

The statistical analysis was carried out using SPSS software (Version 11.5). The correlation between quantitative and qualitative variables was evaluated using a t-test, while the Spearman and Pearson correlation was used to assess the correlation between quantitative variables. The Chi-square test was applied for qualitative variables. The confidence interval was estimated at $95 \%$.

\section{Results}

There were 46 (38.3\%) males and 74 (61.7\%) females with mean \pm SD age of $52.8 \pm 16.7$ years. Patients in both groups of intervention and control were similar regarding their demographic characteristics and comorbidities (Table 1).

\begin{tabular}{|c|c|c|c|}
\hline Variable & $\begin{array}{c}\text { Control }(n=60) \\
\text { mean } \pm S D\end{array}$ & $\begin{array}{c}\text { Case }(n=60) \\
\text { mean } \pm S D\end{array}$ & P-value \\
\hline Age (year) & $54.1 \pm 17.4$ & $51.1 \pm 15.2$ & 0.50 \\
\hline BMI & $25.3 \pm 3.8$ & $23.5 \pm 4.3$ & 0.14 \\
\hline Basic CR (mg/dl) & $1.1 \pm 0.3$ & $1.1 \pm 0.3$ & 0.33 \\
\hline Basic GFR (ml/min) & $77.6 \pm 23.5$ & $77.5 \pm 32.3$ & 0.98 \\
\hline History of MI & $7.1 \%$ & $3.6 \%$ & 0.15 \\
\hline Atrial fibrillation history & & 0 & 0.99 \\
\hline Chronic heart disease & $7.2 \%$ & $3.6 \%$ & 0.31 \\
\hline Hypertension history & $25 \%$ & $\% 52$ & 0.99 \\
\hline Hyperlipidemia history & $17.9 \%$ & $7.1 \%$ & 0.084 \\
\hline COPD history & $17 \%$ & $3.6 \%$ & 0.55 \\
\hline Diabetes history & $21.4 \%$ & $17.9 \%$ & 0.73 \\
\hline Renal failure history & 0 & 0 & 0.99 \\
\hline Anemia history & 0 & 0 & 0.99 \\
\hline Smoking & $25 \%$ & $17.9 \%$ & 0.51 \\
\hline Opium addiction & $10.7 \%$ & $10.7 \%$ & 0.99 \\
\hline
\end{tabular}




\begin{tabular}{|c|c|c|c|}
\hline Variable & SE Group & Control Group & P-value \\
\hline Mechanical ventilation time (h) & $18.64 \pm 7.7$ & $20.47 \pm 4.2$ & 0.46 \\
\hline Time of operation (h) & $7.7 \pm 3$ & $4.1 \pm 3.3$ & 0.049 \\
\hline Cross-clamp time (min) & $40.17 \pm 8.6$ & $52.21 \pm 5.5$ & 0.030 \\
\hline Time of pump & $50.19 \pm 4.2$ & $63.26 \pm 2.2$ & 0.043 \\
\hline Need for pack cell & $1.82 \pm 1.11$ & $1.86 \pm 0.81$ & 0.91 \\
\hline Need for FFP & $1.43 \pm 0.58$ & $2.24 \pm 1.21$ & 0.028 \\
\hline Need for platelets & $2.75 \pm 0.95$ & $2.50 \pm 1.43$ & 0.77 \\
\hline Post-operative max Cr (mg/dl) & $4.0 \pm 2.1$ & $5.0 \pm 3.1$ & 71.0 \\
\hline Days to maximum $\mathrm{Cr}$ & $6.1 \pm 4.2$ & $0.1 \pm 1.2$ & 29.0 \\
\hline Minimum postoperative GFR (ml/min) & $7.34 \pm 3.71$ & $4.25 \pm 1.71$ & 92.0 \\
\hline Maximum percentage of $\mathrm{Cr}$ change after surgery & $3.40 \pm 5.20$ & $7.38 \pm 4.15$ & 62.0 \\
\hline Maximum percentage of GFR change after surgery & $1.41 \pm 5.14$ & $3.36 \pm 3.16$ & 85.0 \\
\hline ICU stay (h) & $18(15)$ & $28(26)$ & 0.023 \\
\hline
\end{tabular}

\begin{tabular}{|c|c|c|c|c|}
\hline \multicolumn{2}{|l|}{ Variable } & $\begin{array}{c}\text { Control group } \\
n=60\end{array}$ & $\begin{array}{c}\text { Se group } \\
n=60\end{array}$ & P-value \\
\hline \multicolumn{2}{|l|}{ AKI cases } & $21.4 \%$ & $17.9 \%$ & 0.73 \\
\hline \multicolumn{2}{|c|}{ Duration to AKI (day) } & $2.2 \pm 0.3$ & $2.2 \pm 0.5$ & $0.87 * *$ \\
\hline \multicolumn{2}{|c|}{ Duration to maximum $\operatorname{Cr}$ (day) } & $3.6 \pm 1.5$ & $3.4 \pm 1.6$ & $0.41 * *$ \\
\hline AKI & Risk & $14.3 \%$ & $7.1 \%$ & \\
\hline Severity & Injury & $0.0 \%$ & $3.6 \%$ & 0.64 \\
\hline (RIFLE criteria) & Failure & $7.1 \%$ & $7.1 \%$ & \\
\hline \multicolumn{2}{|c|}{ Cases with renal function return } & $10.7 \%$ & $7.1 \%$ & 0.32 \\
\hline \multicolumn{2}{|c|}{ Days to return to basic renal function } & $6.2 \pm 2.7$ & $4.1 \pm 1.8$ & $0.18 * *$ \\
\hline
\end{tabular}

Surgical and postsurgical characteristics are presented in Table 2 . There was not any significant difference between the Se and the control group in terms of the mean score of the European System for Cardiac Operative Risk Evaluation $(1.38 \pm 0.7$ Vs. $1.30 \pm 0.6$, respectively; $P=0.15$ ).

Based on RIFLE criteria, AKI occurred in $11(17.9 \%)$ patients in the Se group and $13(21.4 \%)$ patients in the control group $(\mathrm{P}=0.73)$, with the highest reported incidence of AKI on the 3rd and 4th postoperative days in both groups. No significant difference was observed between the two groups in terms of the frequency of the patients who were at the risk, injury, or failure stages $(\mathrm{P}=0.64)$ (Table 3).

Considering the AKIN criteria, 17 (28.6\%) and 21 (35.7\%) patients developed AKI in Se and the control group, respectively $(\mathrm{P}=0.55)$ (Table 4). The most frequent stage of AKI among patients was the first stage in both groups.

\begin{tabular}{|c|c|c|c|c|}
\hline \multicolumn{2}{|l|}{ Variable } & $\begin{array}{c}\text { Control group } \\
n=60\end{array}$ & $\begin{array}{c}\text { Se group } \\
n=60\end{array}$ & P-value \\
\hline \multicolumn{2}{|l|}{ CASES AKI } & $35.7 \%$ & $28.6 \%$ & 0.55 \\
\hline \multirow{2}{*}{\multicolumn{2}{|c|}{$\begin{array}{l}\text { FIRST day of AKI } \\
\text { AKI maximum severity day }\end{array}$}} & $3.3 \pm 1.3$ & $2.9 \pm 1.2$ & $0.14 * *$ \\
\hline & & $3.8 \pm 1.9$ & $3.4 \pm 2.2$ & $0.26 * *$ \\
\hline AKI & Stage1 & $28.6 \%$ & $14.3 \%$ & \\
\hline Maximum & Stage 2 & $3.6 \%$ & $7.1 \%$ & 0.53 \\
\hline severity & Stage 3 & $3.6 \%$ & $7.1 \%$ & \\
\hline \multicolumn{2}{|c|}{ cases with renal function return } & $17.9 \%$ & $7.1 \%$ & 0.22 \\
\hline
\end{tabular}

*Chi-square test

**Independent t-test

No significant difference was observed between the mean \pm SD post-operative maximum creatinine level in Se $(1.3 \pm 0.86 \mathrm{mg} / \mathrm{dl})$ and the control group $(1.2 \pm 0.4 \mathrm{mg} / \mathrm{dl})(\mathrm{P}=0.71)$. The mean $\pm \mathrm{SD}$ duration of serum creatinine rise in both groups was $3.58 \pm 1.9$ and 3.4 days which was statistically similar in the two groups.

\section{Discussion}

Patients who undergo on-pump CABG surgery could be affected by different ischemic events including cardioplegic arrest induction, microembolic events, reperfusion of the myocardium via surgical revascularization, and cardioplegic arrest termination (14). There has been increasing evidence that the application of cardio-pulmonary bypass (CPB) using a heart-lung machine for open-heart surgery might be the cause of some of these complications and be associated with pre-and postoperative stress responses which can result in postoperative organ dysfunction $(4,15)$. 
Pretreatment with antioxidants, such as Se is suggested to attenuate the inflammation. Se plays an important role in the anti-inflammatory process and elevation of antioxidant capacities via at least 25 selenoproteins including glutathione peroxidases, thioredoxin reductases, selenoprotein $\mathrm{P}$, and iodothyronine deiodinases (9). There is increasing evidence suggesting that Se serum concentration declines following surgery and remains low for a period of several days to weeks. This reduction is associated with the elevation of reactive oxygen species (ROS) and the severity of illness $(6,16,17)$. On the other hand, post-injury normalization of Se status fails to reduce oxidative stress (17). Therefore, it is postulated that a preemptive approach is preferred.

Cardiac surgery is an ideal model to investigate the efficacy of preemptive Se due to its predictable onset of oxidative injury and can reproducibly prompt ischemia-reperfusion injury. Therefore, onpump CABG with cardioplegic arrest provides ideal circumstances to evaluate the potential injury that can be caused by oxidative stress $(8,10)$. Therefore, this randomized control trial was conducted to evaluate the protective effect of Se in on-pump cardiac surgery.

The relation between preoperative Se administration and cardiovascular outcomes has been reported in several previous studies. On the other hand, some other clinical trials resulted in conflicting results (18-20). Amini et al. reported that administration of neither Se nor vitamin C could reduce the development of AKI following off-pump $\mathrm{CABG}$, which was consistent with the results of the present study (21).

It has been reported that the duration of surgery has a great impact on neuroendocrine hormonal release. Furthermore, the declined levels of intraoperative Se are correlated with CPB duration (20). Therefore, post-operative Se concentration may have predictive value for the later development of multi-organ failure including AKI. It was observed that duration of surgery, pump time, and cross clamp time were significantly longer in the Se group that have been proposed as risk factors for occurrence of AKI. However, these did not affect development of AKI, probably due to the protective role of Se in onpump surgeries.

Patients received more FFP in the Se group in the present study. Nevertheless, unlike a strong association between transfusion of RBC and AKI (22), administration of FFP has not been reported to be a risk factor for the development of AKI after cardiac surgery.

In 2020, physicians in the University of Tehran, Tehran, Iran, conducted a study on 100 patients who had undergone CABG and evaluated the correlation between serum Se level and surgery outcomes. The results of the study showed that patients with reduced Se levels are at an increased risk of longer hospitalization, longer CPB time, and longer duration of surgery. However, they did not consider the frequency of AKI in their study (23).

In 2019, anesthesiologists in Germany published a review study discussing the effects of low levels of preoperative Se level on patient's outcomes following the surgery. Unlike the result of the present study, they revealed that low levels of Se may cause chronic cardiovascular disease and also lead to organ dysfunction, such as kidney dysfunction in patients following the cardiac surgery (24).

Physicians in Turkey conducted a study in 2019 to evaluate the effect of $\mathrm{Se}$ on docetaxel-induced toxicity. Docetaxel is a chemotherapeutic agent which is used as a treatment for various types of cancers. Based on their results, Se seems to be an antioxidant agent which upregulates Glutathione in kidney cells and leads to recovery from adverse events of docetaxel by apoptosis inhibition. The combined therapy of Se and Docetaxel is recommended as a result (25).

Regarding the limitation of the present study, one can refer to the difference between the two groups in terms of duration of surgery, pump time, and crossclamp time that might affect the results. Therefore, further studies are required to exclude these potential confounding factors. Other limitations included the restriction regarding the long-term follow-up of all patients after ICU discharge and the lack of administration of the IV form of Se due to financial restrictions.

\section{Conclusion}

Although it was not possible to prove the effect of Se in AKI prevention in CABG patients, it is believed that further studies should be designed to evaluate the effect of Se in this context.

\section{Acknowledgments}

This study is part of an internal medicine assistant student dissertation, in Mashhad University of Medical Sciences, Mashhad, Iran (Project No 931605).

\section{Footnotes}

Authors' contribution: AAZ, SHA, HM were the principal investigators of the study. MS, KS, and TZ prepared the concept and design. AZ and KS revised the manuscript and made the critical evaluation of the intellectual contents.

Ethical approval: The study protocol was approved by Ethics Committee in Mashhad University of Medical sciences, Mashhad, Iran (No 931002).

Funding/Support: This study was financially supported by Mashhad University of Medical Sciences, Mashhad, Iran (Grant\#931605).

Conflicts of Interest: The authors declare they have 
no conflicts of interests regarding the publication of this study.

\section{References}

1. Kwiatkowski DM, Price E, Axelrod DM, Romfh AW, Han BS, Sutherland SM, et al. Incidence, risk factors, and outcomes of acute kidney injury in adults undergoing surgery for congenital heart disease. Cardiol Young. 2016;27(6):1068-75. doi: 10.1017/S1047951116002067. [PubMed: 27869053].

2. Amini S, Abbaspour H, Morovatdar N, Robabi HN, Soltani G, Tashnizi MA. Risk factors and outcome of acute kidney injury after congenital heart surgery: a prospective observational study. Indian J Crit Care Med. 2017;21(12):847-51. doi: 10.4103/ijccm.IJCCM_459_16. [PubMed: 29307966].

3. Schopka S, Diez C, Camboni D, Floerchinger B, Schmid C, Hilker M. Impact of cardiopulmonary bypass on acute kidney injury following coronary artery bypass grafting: a matched pair analysis. J Cardiothorac Surg. 2014;9:20. doi: 10.1186/17498090-9-20. [PubMed: 24438155].

4. Hori D, Katz NM, Fine DM, Ono M, Barodka VM, Lester LC, et al. Defining oliguria during cardiopulmonary bypass and its relationship with cardiac surgery-associated acute kidney injury. $B r J$ Anaesth. 2016;117(6):733-40. doi: 10.1093/bja/aew340. [PubMed: 27956671].

5. Spunda R, Valek M, Salmay M, Prskavec T, Pecha O, Lindner J, et al. Differential impact on acute kidney injury incidence between on- and off pump coronary artery bypass grafting in octogenarians. Biomed Pap Med Fac Univ Palacky Olomouc Czech Repub. 2015;159(3):449-54. doi: 10.5507/bp.2014.023. [PubMed: 24881588].

6. Corredor C, Thomson R, Al-Subaie N. Long-term consequences of acute kidney injury after cardiac surgery: a systematic review and meta-analysis. J Cardiothorac Vasc Anesth. 2016;30(1):6975. doi: 10.1053/j.jvca.2015.07.013. [PubMed: 26482483].

7. Mao H, Katz N, Ariyanon W, Blanca-Martos L, Adybelli Z, Giuliani $A$, et al. Cardiac surgery-associated acute kidney injury. Cardiorenal Med. 2013;3(3):178-99. doi: 10.1159/000353134. [PubMed: 24454314].

8. Lassnigg A, Schmidlin D, Mouhieddine M, Bachmann LM, Druml W, Bauer P, et al. Minimal changes of serum creatinine predict prognosis in patients after cardiothoracic surgery: a prospective cohort study. J Am Soc Nephrol. 2004;15(6):1597605. doi: 10.1097/01.asn.0000130340.93930.dd. [PubMed: 15153571].

9. Joannidis M. Medical therapy of acute kidney injury. Acta Clin Belg. 2007;62(Suppl 2):353-6. doi: 10.1179/acb.2007.079. [PubMed: 18283998]

10. Bragadottir G, Redfors B, Ricksten SE. Mannitol increases renal blood flow and maintains filtration fraction and oxygenation in postoperative acute kidney injury: a prospective interventional study. Crit Care. 2012;16(4):R159. doi: 10.1186/cc11480. [PubMed: 22901953].

11. Mitaka C, Ohnuma T, Murayama T, Kunimoto F, Nagashima M, Takei $\mathrm{T}$, et al. Effects of low-dose atrial natriuretic peptide infusion on cardiac surgery-associated acute kidney injury: A multicenter randomized controlled trial. J Crit Care. 2016;38:253-8. doi: 10.1016/j.jcrc.2016.12.004. [PubMed: 27997877].

12. Iglesias P, Selgas R, Romero S, Díez JJ. Selenium and kidney disease. J Nephrol. 2013;26(02):266-72. doi: 10.5301/jn.5000213. [PubMed: 23023721].

13. Ghorbani A, Omidvar B, Parsi A. Protective effect of selenium on cisplatin induced nephrotoxicity: a double-blind controlled randomized clinical trial. J Nephropathol. 2013;2(2):129-34. doi: 10.12860/JNP.2013.21. [PubMed: 24475439].

14. Mohammadpour A, Amini S, Shakeri M, Mirzaie S. Comparing the effect of open and closed endotracheal suctioning on patients' hemodynamic factors after coronary artery bypass grafting under mechanical ventilation. Horizon Med Sci. 2014;20(2):87-92.

15. Sheybani S, Boustan S, Amini S, Najaf Najafi M, Abbasi Tashnizi M, Zirak N. Frequency of acute kidney injury in patients treated with normal saline after off-pump coronary artery bypass grafting. J Cardio Thorac Med. 2017;5(1):533-7.

16. Mao H, Katz N, Ariyanon W, Blanca-Martos L, Adýbelli Z, Giuliani A, et al. Cardiac surgery-associated acute kidney injury. Cardiorenal Med. 2013;3(3):178-99. doi: 10.1159/000353134. [PubMed: 24454314].

17. Raja SG, Shah J, Navaratnarajah M, Amin F, Amrani M Outcomes and predictors of mortality and stroke after onpump and off-pump coronary artery bypass surgery in octogenarians. Innovations. 2013;8(4):269-75. doi: 10.1097/IMI.0000000000000000. [PubMed: 24145971].

18. Reents W, Hilker M, Börgermann J, Albert M, Plötze K, Zacher M, et al. Acute kidney injury after on-pump or off-pump coronary artery bypass grafting in elderly patients. Ann Thorac Surg. 2014;98(1):9-15. doi: 10.1016/j.athoracsur.2014.01.088. [PubMed: 24881861].

19. Stoppe C, Rex S, Goetzenich A, Kraemer S, Emontzpohl C, Soppert J, et al. Interaction of MIF family proteins in myocardial ischemia.reperfusion damage and their influence on clinical outcome of cardiac surgery patients. Antioxid Redox Signal. 2015;23(11):865-79. doi: 10.1089/ars.2014.6243. [PubMed: 26234719].

20. Stevanovic A, Coburn M, Menon A, Rossaint R, Heyland D, Schälte G, et al. The importance of intraoperative selenium blood levels on organ dysfunction in patients undergoing offpump cardiac surgery: a randomised controlled trial. PloS One 2014;9(8):e104222. doi: 10.1371/journal.pone.0104222. [PubMed: 25118980].

21. Amini S, Robabi HN, Tashnizi MA, Vakili V. Selenium, vitamin C and N-Acetylcysteine do not reduce the risk of acute kidney injury after off-pump CABG: a randomized clinical trial. $\mathrm{Braz} J$ Cardiovasc Surg. 2018;33(2):129-34. doi: 10.21470/16789741-2017-0071. [PubMed: 29898141].

22. Amini S, Najafi MN, Karrari SP, Mashhadi ME, Mirzaei S, Tashnizi MA, et al. Risk factors and outcome of acute kidney injury after isolated CABG surgery: a prospective cohort study. Braz J Cardiovasc Surg. 2019;34(1):70-5. doi: 10.21470/16789741-2017-0209. [PubMed: 30810677].

23. Eslami G, Salehi R, Samaee H, Habibi V, Shokrzadeh M, Moradimajd P. Relationship between selenium trace and patient outcome after open-heart surgery. Anesth Pain Med. 2020;10(4):e105895. doi: 10.5812/aapm.105895. [PubMed: 33134151].

24. Wendt S, Schomburg L, Manzanares W, Stoppe C. Selenium in cardiac surgery. Nutr Clin Pract. 2019;34(4):528-39. doi: 10.1002/ncp.10326. [PubMed: 31172596].

25. Baș E, Naziroğlu M. Selenium attenuates docetaxelinduced apoptosis and mitochondrial oxidative stress in kidney cells. Anticancer Drugs. 2019;30(4):339-46. doi: 10.1097/CAD.0000000000000723. [PubMed: 30875346]. 